\title{
Prevalence of Long-term Post COVID-19 Symptom and Blood Group Correlation
}

\author{
Nuzhat Banu*, Aljawhara Abdullah Algosaibi, Khaton Abdullah Alhazza, Layla Makki Al Janbi, Mohammad Daud Ali, Ayaz Ahmad \\ Department of Pharmacy, Mohammad Al-Mana College for Medical Sciences, Abdulrazaq Bin Hammam Street, As Safa, Dammam, SAUDI ARABIA.
}

\begin{abstract}
Background: The aim of the present work is to anticipate and investigate long-term symptoms in COVID-19 survivors and their correlation with the blood groups. Methods: A prospective cross-sectional survey based study was conducted amongst COVID 19 survivors in the community of eastern province, Saudi Arabia. The target population was adult, $>20$ years old, Saudi citizen, who lives in Eastern Province. The survey was conducted online through social media. Results: In our research 169 self-reported positive COVID-19 patients participated among which 60 (35.5\%) were males and 109 (64.4\%) were female. Highest percentage were among the younger age group 21-30 years, 60 (35.5\%). O+ constitutes the highest percentage $(45 \%)$ followed by $B+(21 \%), A+(18 \%), A B(6 \%), O-(5 \%)$, $\mathrm{A}-(4 \%)$, and $\mathrm{B}-(1 \%)$. Patients suffering with chronic diseases $24(14.2 \%)$ showed more severe symptoms, $5(20.83 \%)(p=0.324)$ than those without any chronic disease $145(85.79 \%), 10(6.89 \%)(p=0.00)$. The hospitalization rate was higher in patients suffering with chronic disease, 7 (29.16\%) than those without any chronic disease, 12 (8.27\%). A- Showed more
\end{abstract}

mild symptoms, 6(85.71\%), followed by moderate, $1(14.28 \%)$ and no severe symptoms $(p=0.011)$. Conclusion: It was observed that the blood group and chronic diseases had significant correlation with the severity of disease and prevalence of symptoms post COVID. Highest positive cases were reported among $\mathrm{O}+$. Severity of disease was highest in $\mathrm{A}+$ and lowest in A-.

Key words: Blood groups, COVIID 19, Chronic disease, Symptom, Saudi Arabia.

\section{Correspondence}

Mrs. Nuzhat Banu,

Lecturer, Department of Pharmacy, Mohammad Al-Mana College for Medical Sciences, Abdulrazaq Bin Hammam Street, As Safa, Dammam-34222, SAUDI ARABIA.

Email id: nuzhat04@yahoo.co.in

DOI: 10.5530/jyp.2021.13.97

\section{INTRODUCTION}

The severe acute respiratory syndrome (SARS) coronavirus-2 is a novel coronavirus belonged to the Coronaviridae family that has now been confirmed as the cause of a recent outbreak of acute odd respiratory infections in Wuhan, China. Coronavirus disease 19 (COVID-19) is a disease caused by this respiratory virus. ${ }^{1}$ Coronavirus infections 2019 (COVID-19) is an infectious disease that started in Wuhan, China and has been reaching the worldwide. ${ }^{2}$

SARS-CoV-2 pathogens invade host cells through the S spike enzyme, which binds to ACE2 for internalization and is assisted mostly by TMPRSS2 protease. The virus's higher virulence factors is due to mutations in the receptor binding region and acquisition of a furan cleavage site in the S spike proteins. ${ }^{3}$ In predisposed patients, the virus's interference with ACE2 can reduce the activity the anti-inflammatory function and increase angiotensin II impact. With the difficulties we face with COVID-19, others have called for the use (or discontinuation) of angiotensin II receptor type 1 (AT1 receptor) blockers and ACE inhibitors during COVID-19 treatment in patients with hypertension disease, and there is no evidence supporting it. ${ }^{3,4}$

Invasion of the virus into the vascular system's lung cells, myocytes, and endothelial cells causes inflammatory responses such as edema, degeneration, and necrosis. Pro inflammatory cytokines such as interleukin IL-6, IL-10, and tumor necrosis factor, granulocyte colony stimulating factor, monocyte chemo attractant protein 1, macrophage inflammatory protein 1 , and increased expression of programmed cell death 1, T-cell immunoglobulin, and mucin region 3 (Tim-3) are all linked to these modifications. Lung injury pathogenesis, hypoxia-related myocyte injury, body immune response, extended myocardial cell harm, and intestinal and cardiopulmonary changes are all influenced by these changes. ${ }^{4}$

The virus spreads once an individual coughs, sneezes, speaks, sings, or breathes strongly. The virus may spread in the form of droplets from their mouth or nostril. These liquid droplets come in various sizes, from massive "respiratory droplets" to tiny "aerosols." COVID-19 has high chance of transmission when the droplets reaches their mouth, nose, or eyes, which has more chances of happening when humans are in close or near contact (less than 1 meter apart) with an infected individual. Aerosol transmission might happen in particular circumstances, such as restaurants, choir sessions, exercise classes, nightclubs, workplaces, and/ or places of worship, where infected people spend long periods of time with others in noisy, poorly ventilated spaces. ${ }^{5}$

An outpatient clinic in Italy reported $87.4 \%$ of patients recovered from COVID-19 and discharged from hospital with persistence of symptoms at a follow-up of 60days from the onset of the first symptoms. Highest percentage of people reported with fatigue, followed by dyspnea, joint pain and chest pain. There were more than half of these patients who complained more than three or more symptoms. Other prevalent symptoms recorded were difficulty breathing, palpitation and orthostatic hypertension which may last for weeks after the mild disease. ${ }^{6,7}$

Long term effects of COVID 19 in patients with chronic diseases is of high importance and shouldn't be neglected along with the treatment of communicable diseases. Although chronic diseases increases the severity of COVID symptoms there are people with non-communicable disease

This is an open access article distributed under the terms of the Creative Commons Attribution-NonCommercial-ShareAlike 4.0 License, which allows others to remix, tweak, and build upon the work non-commercially, as long as the author is credited and the new creations are licensed under the identical terms. 
who survived from COVID-19 but it effected their preexisting clinical conditions. ${ }^{8}$ Furthermore, dementia and other neurogenerative disorders due to peripheral inflammation are observed in patients recovered. ${ }^{9}$ Reduced lung function, psychological disturbances and difficulty to exercise were common in SARS and MERS survivors. ${ }^{10}$

Blood group correlation with infection causing organisms had been studied in various earlier research. The antigen for blood group in the erythrocytes interacts with the microorganisms, virus, bacteria and fungi in a different manner due to the variation in their expression and shows difference in severity of the infection. Some of the microorganisms that have been in association with the blood groups were Helicobacter pylori, Vibrio cholerae, hepatitis $\mathrm{C}$ virus, human immunodeficiency virus and SARS. ${ }^{11-13}$

The aim of the present work is to anticipate and investigate similar longterm symptoms in COVID-19 survivors and their correlation with the blood groups.

\section{MATERIALS AND METHODS}

A prospective cross-sectional survey based study was conducted amongst community in eastern province, Saudi Arabia in between $1^{\text {st }}$ February to $30^{\text {th }}$ April 2021.

\section{Study Design and area and settings}

Online survey based study was conducted in the community of Eastern Province, Saudi Arabia. This is an observational, descriptive, crosssectional study design, where all participants who fulfill the inclusion (COVID-19 patients) and exclusion criteria (Non COVID-19) will be invited to fill-up a self-administered, close-ended, structured and previously validated, questionnaire to identify prevalence of long- term symptoms in COVID-19 survivors and their correlation with the blood group.

\section{Identification of study participants}

The target population was adult, $>20$ years old, Saudi citizen, who lives in Eastern Province. The survey link was sent through the social media among community of identified population. The survey was filled by both genders based on their willingness to participate in the study.

\section{Study tool and Validation of the study tool}

A 22-item questionnaire was utilized to attain the objectives of the study. The contents of the tool was a self-developed questionnaire that was designed, keeping the objective of study in mind. The questionnaire is composed of three sections. The first section is about the basic demographic features of our study population. The second section measures the participant's health status. The third sections was related to post COVID- 19 symptoms. After developing a Google form, trial survey was also done by researcher and final checking of the responses was done by the first author. After checking the response and validation of response and questionnaire, survey link was disseminated through social media in the community. Prior to closing the survey a reminder was given to fill the survey and responses received after closing the survey was not included in the study.

\section{Ethical considerations}

Prior to conduction of study mentioned study proposal was approved from scientific research Unit (SRU) of MACHS. Ethical approval number is $\mathrm{SR} / \mathrm{RP} / 69$. Furthermore, any information disclosing respondent identity was excluded from the tool. Prior to participation in the study online consent was also obtained from the respondents who took part in the study.

\section{Statistical analysis}

All the survey response was archived in Microsoft Excel Version 2019. All the response was analysed in terms of percentage and frequency by using Microsoft Excel Version 2019. Significance level of questionnaire response was also derived by using chi-square test. All the value of chi-square test 0.05 considers as statistically significant.

\section{RESULTS}

Here, we report the analysis of 169 self-reported positive COVID-19 cases with long-term symptoms.

\section{Demography characteristics}

Out of 169 COVID positive patients, 60 (35.5\%) were males and 109 (64.4\%) were female. Highest percentage were among the younger age group 21-30 years, $60(35.5 \%)$ and least were among those above 60 years, $9(5.32 \%)$ with $82(48.52 \%)$ married $75(44.37 \%)$ non married participants. $60(35.50 \%)$ were students followed by those working in private31 (18.34\%) and government sector 25(14.79\%) respectively. Table 1 displays the detail demographic characteristics of the study participants.

\section{Occurrence of the COVID 19 infection in different blood groups}

$\mathrm{O}+$ constitutes the highest percentage (45\%) followed by $\mathrm{B}+(21 \%)$, $\mathrm{A}+(18 \%), \mathrm{AB}(6 \%), \mathrm{O}-(5 \%), \mathrm{A}-(4 \%)$, and $\mathrm{B}-(1 \%)$. Figure 1 shows the occurrence of the COVID 19 infection in different blood groups.

\section{Table 1: Demographic characteristics of study participants ( $n=169$ ).}

\begin{tabular}{cc}
\hline Variables & Responses $\mathbf{n}(\%)$ \\
\hline Gender & $60(35.5 \%)$ \\
Male & $109(64.4 \%)$ \\
Female & \\
Age (years) & $35(20.7 \%)$ \\
$<20$ & $60(35.5 \%)$ \\
$21-30$ & $38(22.4 \%)$ \\
$31-40$ & $13(7.74 \%)$ \\
$41-50$ & $14(7.69 \%)$ \\
$51-60$ & $9(5.32 \%)$ \\
$>60$ & \\
Marital status & $82(48.52 \%)$ \\
Married & $75(44.37 \%)$ \\
Non-married & $8(4.73 \%)$ \\
Divorced & $4(2.36 \%)$ \\
Widow & \\
Employment status & $60(35.50 \%)$ \\
Student & $16(9.46 \%)$ \\
Unemployed & $25(14.79 \%)$ \\
Government & $31(18.34 \%)$ \\
Private & $24(14.20 \%)$ \\
Housewife & $6(3.55 \%)$ \\
Health care worker & $7(4.14 \%)$ \\
Retired & \\
No of family member & $16(9.46 \%)$ \\
1 & $18(10.65 \%)$ \\
2 & $135(79.88 \%)$ \\
\hline &
\end{tabular}




\section{Frequency of symptoms observed post COVID in different blood groups}

The incidence of feeling tired was observed highest in $\mathrm{A}+,(30 \%)$ followed by O-, 2(22.22\%), O+, 14 (18.42\%), B+, 6(16.66\%), A-, 1(14.2\%) and none in B-. Anxiety was highest in B-, 1(50\%), followed by O-2(22.22\%), A+, 5(16.66\%), B+, 4(11.11\%), AB, 1(11.11\%) and none in B- and A-.Depression was not observed in A-, B-, but was observed the highest in $\mathrm{A}+, 9(30 \%), \mathrm{O}-, 2(22.22 \%), \mathrm{O}+, 14(18.42 \%), \mathrm{B}+, 5(13.88 \%)$, $\mathrm{AB}, 1(11.11 \%)$ and none in other groups. Difficulty in thinking and concentration was not observed in most of the blood groups i.e. A-, $\mathrm{AB}, \mathrm{B}-, \mathrm{O}-$, whereas it was highest in $\mathrm{O}+, 5(6.57 \%), \mathrm{B}+, 2(5.55 \%), \mathrm{A}+$, $1(3.33 \%)$. Ophthalmic problems were observed in 4 of the groups with highest percentage in $\mathrm{O}-, 2(22.22 \%), \mathrm{A}+, 4(13.33 \%), \mathrm{O}+, 3(3.94 \%), \mathrm{B}+$ $1(2.77 \%)$ and absent in rest of the groups. Headache was highly prevalent in $\mathrm{AB}, 3(33.33 \%), \mathrm{A}+, 7(23.33 \%), \mathrm{O}-, 2(22.22 \%), \mathrm{A}-, 1(14.2 \%)$ and $\mathrm{O}+$, $4(5.26 \%)$ and absent in rest of the groups. Hair loss was observed in some of the groups with high prevalence in B-, 1(50\%),A+, 11(36.66\%), $\mathrm{AB}, 2(22.22 \%), \mathrm{A}-, 1(14.2 \%), \mathrm{B}+, 4(11.11 \%), \mathrm{O}+, 8(10.52 \%)$, and absent in O-. High body temperature was less prevalent post COVID and was observed in few groups, $\mathrm{B}+, 2(5.55 \%), \mathrm{A}+, 1(3.33 \%), \mathrm{O}+, 2$ (2.63\%). Joint pain was observed in $\mathrm{O}-, 2(22.22 \%), \mathrm{A}+, 5(16.66 \%), \mathrm{A}-, 1(14.2 \%), \mathrm{O}+$,

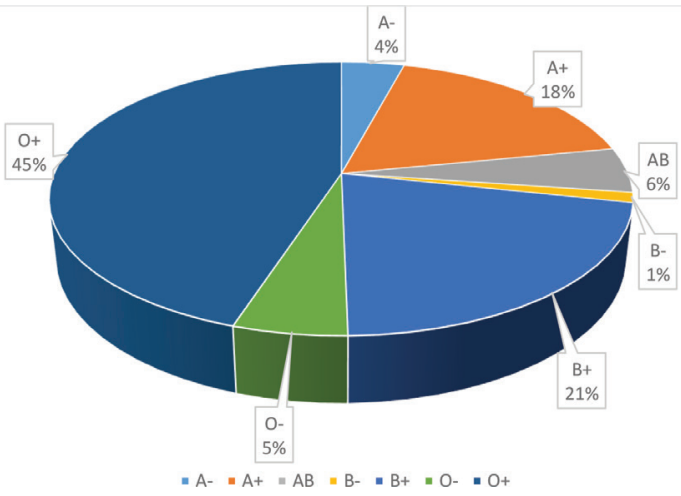

Figure 1: Positivity of COVID 19 in different blood group $n=169$.
9(11.84\%), B+, 2(5.55\%). Difficulty in breathing was observed highest in B-, 1(50\%), A+, 9(30\%),AB, 2(22.22\%),O+, 12(15.78\%),B+, 5(13.88\%), and absent in rest of the groups. Loss of taste and smell is the symptom that was prevalent post COVID in all of the groups with highest in B-, 1(50\%), A+, 13(43.33\%), O-, 3(33.33\%), O+, 22(28.94\%), A-, 1(14.2\%), $\mathrm{AB}, 1(11.11 \%) . \mathrm{O}-, \mathrm{1}(11.11 \%), \mathrm{B}+, 4(11.11 \%)$. Cough was absent in Aand $\mathrm{B}-$,whereas the highest percentage was shown in $\mathrm{O}+, 10(13.15 \%)$, and $\mathrm{AB}, \mathrm{B}+, \mathrm{O}$-were at the same level of $11.11 \%$.There were no symptoms reported by some of the patients in each group with highest in A-, 5(57.14\%)followed by B-, 1(50\%), O-, 3(33.33\%), B+, 11(30.55\%), O+, $22(28.94 \%), A+, 4(13.33 \%)$. Table 2 describes the frequency of symptoms observed post COVID in different blood groups:

\section{Severity of disease in patients suffering with and without chronic disease}

It was observed that the patients suffering with chronic diseases $24(14.2 \%)$ showed more severe symptoms, $5(20.83 \%)(p=0.324)$ than those without any chronic disease $145(85.79 \%), 10(6.89 \%)$ and it was found to be statistically significant $(p=0.00)$. Mild symptoms were observed the highest in patients without any chronic disease 74(51.03\%), than those with chronic disease $8(33.33 \%)$. Similarly patients suffering from chronic disease showed slightly higher moderate symptoms, 11 $(45.83 \%)$ that those without any chronic disease 61 (42.06\%). Table 3 shows severity of disease in patients suffering with and without chronic disease.

\section{Hospitalization rate in patients with chronic disease}

Although there were reported cases of hospitalization, there were majority of the cases that didn't require hospitalization. When compared, it was observed that the hospitalization rate was higher in patients suffering with chronic disease, 7 (29.16\%) than those without any chronic disease, $12(8.27 \%)$. Table 4 shows hospitalization rate in patients.

\section{Severity of disease in different blood groups}

The observations were as follows. A-Showed more mild symptoms, $6(85.71 \%)$, followed by moderate, $1(14.28 \%)$ and no severe symptoms ( $p=0.011$ ), that was found to be statistically significant. A+ showed more

Table 2: Frequency of symptoms observed post COVID in different blood groups.

\begin{tabular}{|c|c|c|c|c|c|c|c|}
\hline $\begin{array}{l}\text { Post COVID } \\
\text { symptoms }\end{array}$ & $A-(n=7)$ & $A+(n=30)$ & $A B(n=9)$ & $B-(n=2)$ & $B+(n=36)$ & $O-(n=9)$ & $0+(n=76)$ \\
\hline Feeling tired & $1(14.2 \%)$ & $9(30 \%)$ & $1(11.11 \%)$ & $0(0 \%)$ & $6(16.66 \%)$ & $2(22.22 \%)$ & $14(18.42 \%)$ \\
\hline Anxiety & $0(0 \%)$ & $5(16.66 \%)$ & $1(11.11 \%)$ & $1(50 \%)$ & $4(11.11 \%)$ & $2(22.22 \%)$ & $9(11.84 \%)$ \\
\hline Depression & $0(0 \%)$ & $9(30 \%)$ & $1(11.11 \%)$ & $0(0 \%)$ & $5(13.88 \%)$ & $2(22.22 \%)$ & $14(18.42 \%)$ \\
\hline $\begin{array}{l}\text { Difficulty in thinking } \\
\text { and concentration }\end{array}$ & $0(0 \%)$ & $1(3.33 \%)$ & $0(0 \%)$ & $0(0 \%)$ & $2(5.55 \%)$ & $0(0 \%)$ & $5(6.57 \%)$ \\
\hline Opthalmics problems & $0(0 \%)$ & $4(13.33 \%)$ & $0(0 \%)$ & $0(0 \%)$ & $1(2.77 \%)$ & $2(22.22 \%)$ & $3(3.94 \%)$ \\
\hline Headache & $1(14.2 \%)$ & $7(23.33 \%)$ & $3(33.33 \%)$ & $0(0 \%)$ & $5(13.88 \%)$ & $2(22.22 \%)$ & $4(5.26 \%)$ \\
\hline Hair loss & $1(14.2 \%)$ & $11(36.66 \%)$ & $2(22.22 \%)$ & $1(50 \%)$ & $4(11.11 \%)$ & $0(0 \%)$ & $8(10.52 \%)$ \\
\hline $\begin{array}{l}\text { High body } \\
\text { temperature }\end{array}$ & $0(0 \%)$ & $1(3.33 \%)$ & $0(0 \%)$ & $0(0 \%)$ & $2(5.55 \%)$ & $0(0 \%)$ & $2(2.63 \%)$ \\
\hline Joint pain & $1(14.2 \%)$ & $5(16.66 \%)$ & $0(0 \%)$ & $0(0 \%)$ & $2(5.55 \%)$ & $2(22.22 \%)$ & $9(11.84 \%)$ \\
\hline Difficulty in breathing & $0(0 \%)$ & $9(30 \%)$ & $2(22.22 \%)$ & $1(50 \%)$ & $5(13.88 \%)$ & $0(0 \%)$ & $12(15.78 \%)$ \\
\hline $\begin{array}{c}\text { Loss of taste and } \\
\text { smell }\end{array}$ & $1(14.2 \%)$ & $13(43.33 \%)$ & $1(11.11 \%)$ & $1(50 \%)$ & $7(19.44 \%)$ & $3(33.33 \%)$ & $22(28.94 \%)$ \\
\hline Cough & $0(0 \%)$ & $2(6.66 \%)$ & $1(11.11 \%)$ & $0(0 \%)$ & $4(11.11 \%)$ & $1(11.11 \%)$ & $10(13.15 \%)$ \\
\hline None & $4(57.14 \%)$ & $4(13.33 \%)$ & $0(0 \%)$ & $1(50 \%)$ & $11(30.55 \%)$ & $3(33.33 \%)$ & $22(28.94 \%)$ \\
\hline
\end{tabular}


Table 3: Severity of disease in patients suffering with and without chronic disease.

\begin{tabular}{ccccc}
\hline \multirow{2}{*}{ Patient } & \multicolumn{3}{c}{ Severity of the disease } \\
\cline { 2 - 5 } & $\begin{array}{c}\text { Mild } \\
\text { symptoms }\end{array}$ & $\begin{array}{c}\text { Moderate } \\
\text { symptoms }\end{array}$ & $\begin{array}{c}\text { Severe } \\
\text { symptoms }\end{array}$ & P-value \\
\hline $\begin{array}{c}\text { Severity of } \\
\text { disease in patients } \\
\text { suffering from } \\
\text { chronic disease } \\
n=24\end{array}$ & $8(33.3 \%)$ & $11(45.83 \%)$ & $5(20.83 \%)$ & 0.324 \\
$\begin{array}{c}\text { Severity of disease } \\
\text { in patients without } \\
\text { any chronic disease } \\
n=145\end{array}$ & $74(51.03 \%)$ & $61(42.06)$ & $10(6.89 \%)$ & $0.00^{*}$ \\
\hline
\end{tabular}

* Significant $p$-Value $(p \leq 0.05)$

Table 4: Hospitalization rate in patients with and without chronic disease $n=169$.

\begin{tabular}{cc}
\hline Type of patient & Hospitalized \\
\hline Suffering with chronic disease $n=24$ & $7(29.16 \%)$ \\
Not suffering with any chronic disease $n=145$ & $12(8.27 \%)$ \\
\hline
\end{tabular}

Table 5: Severity of disease in different blood groups.

\begin{tabular}{cccccccc}
\hline \multirow{2}{*}{$\begin{array}{c}\text { Severity } \\
\text { of disease }\end{array}$} & \multicolumn{7}{c}{ Blood group } \\
& A- & A+ & AB & B- & B+ & O- & O+ \\
& $n=7$ & $n=30$ & $n=9$ & $n=2$ & $n=36$ & $n=9$ & $n=76$ \\
\hline Mild & $6(85.71)$ & $12(40)$ & $4(44.44)$ & $0(0)$ & $18(50)$ & $5(55.55)$ & $37(48.68)$ \\
Moderate & $1(14.28)$ & $14(46.66)$ & $5(55.55)$ & $1(50)$ & $16(44.44)$ & $4(44.44)$ & $31(40.78)$ \\
severe & $0(0)$ & $4(13.33)$ & $0(0)$ & $1(50)$ & $2(5.55)$ & $0(0)$ & $8(10.52)$ \\
$P$-value & $0.011^{*}$ & 0.060 & 0.898 & 0.060 & $0.00073^{*}$ & 0.096 & $0.00^{*}$ \\
\hline
\end{tabular}

moderate symptoms $14(46.66 \%)$, followed by mild symptoms $12(40 \%)$, and severe symptoms $1(13.33 \%)(p=0.060)$. AB showed more moderate symptoms 5(55.55\%), followed by mild symptoms $4(44.44 \%)$ and no severe symptoms $(p=0.898)$. B- showed no mild symptoms but equal moderate and severe symptoms $1(50 \%)(p=0.060)$. B+ showed higher mild symptoms 18(50\%), followed by moderate symptoms $16(44.44 \%)$, and least severe symptoms $2(5.55 \%)(p=0.00073)$. O- showed highest mild symptoms 5(55.55\%) followed by moderate $16(44.44 \%)$ and severe symptoms were not reported $0(0 \%)(p=0.096) . \mathrm{O}+$ showed highest mild symptoms $37(48.68 \%)$ followed by moderate symptoms $31(40.78 \%)$ and severe symptoms $8(10.52 \%)(p=0.00)$ and was found to be statistically significant. Table 5 shows severity of disease in different blood groups.

\section{DISCUSSION}

This study evaluated prevalence of long term symptoms in COVID 19 survivors in comparison to their blood groups.

In our study female were higher than male whereas in another study conducted by Mustafa Çakır male were higher than female. ${ }^{14}$ More than one symptom were reported by each patient, this was in line with a study conducted by Elizabeth T. Cirulli. ${ }^{15}$ It was observed that the COVID 19 positivity was observed the maximum in $\mathrm{O}+$. This is in contrast to a study that states that the COVID -19 positivity was least in O blood group and high in $\mathrm{A}, \mathrm{AB}$ and $\mathrm{B} .{ }^{11}$ Loss of taste and smell was observed in all the blood groups with highest prevalence in O-. Feeling tired was highest in A+, Anxiety in B-, and depression in A+. Difficulty in thinking and concentration was observed in few blood groups like $\mathrm{A}+$, $\mathrm{B}+$ and $\mathrm{O}+$. Ophthalmic problems were reported in $\mathrm{A}+, \mathrm{B}+, \mathrm{O}+$ and O-. Anxiety, hair loss and Headache was observed in almost all groups. High temperature was not reported in many groups except few like A+, $\mathrm{B}+$ and $\mathrm{O}+$ with low frequency. Difficulty in breathing was observed in most of the groups with highest in $\mathrm{O}+$ and none in $\mathrm{A}$ - and $\mathrm{O}-$ - Cough was reported in some groups with highest prevalence in $\mathrm{O}+$. A study conducted by Elizabeth T. Cirulli also showed that anosmia, ageusia, difficulty concentrating, dyspnea, memory loss, confusion, headache, heart palpitations, chest pain, pain with deep breaths, dizziness, and tachycardia were the symptoms reported by patients post COVID. ${ }^{15}$

Patients suffering with chronic disease were $14.2 \%$ which is in contrast to a study conducted by Mustafa Çakır where he reported the patients with chronic diseases to be $18 \% .{ }^{14}$ When compared to severity of disease, it was observed that the patients with chronic diseases showed more moderate symptoms than those without chronic diseases which had more mild symptoms. Severity of disease and hospitalization was highest reported in those patients with chronic diseases than without it. This was in parallel to another study that reported that the severity of disease was highest in patients suffering with chronic diseases like hypertension, cardiovascular disease and asthma. ${ }^{16}$

When severity of disease was observed in different blood groups it showed that mild symptoms were highest in A- and severe symptoms were highest in $\mathrm{A}+$. Most of the blood groups had mild to moderate symptoms except $\mathrm{O}+, \mathrm{A}+, \mathrm{B}+$ and $\mathrm{B}$ - who were observed to have some patients suffering with severe disease. Severity of disease with different blood group was found to be significant in $\mathrm{A}-, \mathrm{O}+$, and $\mathrm{B}$. There was another study that showed that, there was no statistically significant difference between symptoms and symptoms other than cough and chronic disease states of the participants according to the blood groups. ${ }^{14}$

\section{CONCLUSION}

It was observed that the blood group and chronic diseases had significant correlation with the severity of disease and prevalence of symptoms post COVID. Highest positive cases were reported among $\mathrm{O}+$. It was observed that the prevalence of symptoms was observed post COVID in almost all the groups with different occurrences. Hospitalization and severity of the disease was highest in those patients with chronic disease than those without chronic disease. Severity of disease was highest in $\mathrm{A}+$ and lowest in A-. Loss of taste and smell was the symptoms the patients in all the groups were suffering post COVID. Maximum patients in A- did not observe any symptoms post COVID. Depression was observed more in $\mathrm{A}+$. Hair loss was observed in $\mathrm{B}-$ and $\mathrm{A}+$. Headache was prevalent in AB. Most patients in most of the blood groups didn't show high temperature post COVID.

\section{CONFLICT OF INTEREST}

All author(s) declared no conflict of interest.

\section{REFERENCES}

1. Ahmad S, Shoaib A, Ali MS, Alam MS, Alam N, Ali M, et al. Epidemiology, risk, myths, pharmacotherapeutic management and socio economic burden due to novel COVID-19: A recent update. Res J Pharm Technol. 2020;13(9):4435-42. doi: 10.5958/0974-360X.2020.00784.2

2. Hormati Ahmad, Shahhamzeh Alireza, Afifian Mahboubeh, Khodadust Fatemeh, Ahmadpour Sajjad. Can COVID-19 present unusual Gl symptoms? J Microbiol Immunol Infect. 2020;53(3):384-5. doi: 10.1016/j.jmii.2020.03.020, PMID 32249184.

3. Yuki Koichi, Fujiogi Miho, Koutsogiannaki Sophia. COVID-19 pathophysiology: A review. Clin Immunol. 2020;215:108427. doi: 10.1016/j.clim.2020.108427.

4. Azer SA. COVID-19: Pathophysiology, diagnosis, complications and investigational therapeutics. New Microbes New Infect. 2020;37(37):100738. 
doi: 10.1016/j.nmni.2020.100738.

5. World Health Organization. Coronavirus disease (COVID-19): how is transmitted. Link; July 9 2020. Q\&A. [last accessed on Apr 29 2021]. Available from: https:// www.who.int/news-room/q-a-detail/coronavirus-disease-covid-19-how-is-ittransmitted.

6. Nalbandian Ani, Sehgal Kartik, Gupta Aakriti, Madhavan Mahesh V, McGroder Claire, Stevens Jacob S, et al. Post-acute COVID-19 syndrome. Nat Med. 2021:27(4):601-15. doi: 10.1038/s41591-021-01283-z, PMID 33753937.

7. Dani Melanie, Dirksen Andreas, Taraborrelli Patricia, Torocastro Miriam, Panagopoulos Dimitrios, Sutton Richard, et al. Autonomic dysfunction in 'long COVID': Rationale, physiology and management strategies. Clin Med (Lond). 2021;21(1):e63-7. doi: 10.7861/clinmed.2020-0896, PMID 33243837.

8. Palmer Katie, Monaco Alessandro, Kivipelto Miia, Onder Graziano, Maggi Stefania, et al. The potential long-term impact of the COVID-19 outbreak on patients with non-communicable diseases in Europe: consequences for healthy ageing. Aging Clin Exp Res. 2020;32(7):1189-94. doi: 10.1007/s40520-02001601-4, PMID 32458356

9. Butler Michael J, Barrientos Ruth M. The impact of nutrition on COVID-19 susceptibility and long-term consequences. Brain Behav Immun. 2020;87(87):53-4. doi: 10.1016/..bbi.2020.04.040, PMID 32311498.

10. Ahmed Hassaan, Patel Kajal, Greenwood Darren C, Halpin Stephen, Lewthwaite Penny, Salawu Abayomi, et al. Long-term clinical outcomes in survivors of severe acute respiratory syndrome and Middle East respiratory syndrome coronavirus outbreaks after hospitalisation or ICU admission: A systematic review and meta-analysis. J Rehabil Med. 2020;52(5 (5)):jrm00063. doi: 10.2340/16501977-2694, PMID 32449782.

11. Yanardag Acik Didar Yanardag, Bankir Mehmet. Relationship of SARS-CoV-2 pandemic with blood groups. Transfus Med Hemother. 2021;48(3):161-7. doi: 10.1159/000515609, PMID 34177420.

12. Berger SA, Young NA, Edberg SC. Relationship between infectious diseases and human blood type. Eur J Clin Microbiol Infect Dis. 1989;8(8):681-9. doi: 10.1007/BF01963752, PMID 2506033.

13. Anstee David J. The relationship between blood groups and disease. Blood. 2010;115(23):4635-43. doi: 10.1182/blood-2010-01-261859, PMID 20308598.

14. Mustafa Çakır. The relationship between blood groups and COVID-19 patients. Erciyes Med J. 2021;43(2):142-5.

15. Cirulli Elizabeth T, Kelly M, Barrett Schiabor, Riffle Stephen, Bolze Alexandre, Neveux Iva, et al. Long-term COVID-19 symptoms in a large unselected population. medRxiv preprint doi: 10.1101/2020.10.07.20208702.

16. Fernández-de-Las-Peñas César, Torres-Macho Juan, Velasco-Arribas Maria, Arias-Navalón Jose A, Guijarro Carlos, Hernández-Barrera Valentín, et al. Similar prevalence of long-term post-COVID symptoms in patients with asthma: A case-control study. J Infect. 2021;83(2):237-79. doi: 10.1016/j.jinf.2021.04.034. PMID 33957161.

Article History: Received: 02-09-2021; Revised: 29-09-2021; Accepted: 27-10-2021.

Cite this article: Banu N, Algosaibi AA, Alhazza KA, Janbi LMA, Ali MD, Ahmad A, Alzahrani MG. Prevalence of Long-term Post COVID-19 Symptom and Blood Group Correlation. J Young Pharm. 2021;13(4):400-4 